\title{
Mechanochemical Preparation and Properties of Nanodimensional Perovskite Materials
}

\author{
Z. Cherkezova-Zheleva*, D. Paneva, I. Yordanova, M. Shopska and H. Kolev \\ Institute of Catalysis, Bulgarian Academy of Sciences, "Acad. G. Bonchev" Str., Bld. 11, 1113 Sofia, Bulgaria
}

\begin{abstract}
The study is focused on the synthesis of $\mathrm{LaMO}_{3}(\mathrm{M}=\mathrm{Co}, \mathrm{Fe}, \mathrm{Mn})$ perovskite materials using combination of precipitation of precursors and mechanical milling at room temperature. Physicochemical properties of products at each step of preparation were studied by powder X-ray diffraction, Mössbauer spectroscopy, infrared spectroscopy (in the middle and far regions) and X-ray photoelectron measurements. As-prepared perovskite powders are composed of nanoparticles with very fine crystallite size (about $15 \mathrm{~nm}$ ) in all cases. The materials have also high dispersion, high extent of microstrains and high level of oxygen vacancies which is very important in relevance to their use as heterogeneous catalysts.
\end{abstract}

DOI: 10.12693/APhysPolA.126.916

PACS: 81.07.-b, 82.80.Ej, 82.80.Pv

\section{Introduction}

The perovskite oxides have the general formula $\mathrm{ABO}_{3}$ where $\mathrm{A}$ and $\mathrm{B}$ denote two different cations. The possibility of synthesizing perovskites by partial substitution of cations in positions A or B gives rise to preparation of compounds with unusual oxidation states in the crystal structure. Nowadays, they are intensively studied due to their physical properties like colossal magnetoresistance, ferroelectricity, superconductivity, etc. [1-5]. Different types of perovskites are used as sensors and catalyst electrodes in fuel cells [1-7]. Study of Fe-, Co- and Mnlantania-based perovskite oxides is one of the main focuses in this regard. In these materials both the bulkoxygen pathway and the interfacial oxygen reduction kinetics play an important role. It has been shown that surface processes such as the surface oxygen exchange and oxygen surface diffusion influence the catalytic performance of materials [2-7]. Oxygen vacancies can be formed by charge imbalances induced by doping of the materials. In perovskite-type materials, the creation of oxygen vacancies strongly depends on environment, temperature and the type and loading of the B-site cations. Oxygen vacancy formation in $\mathrm{Co}, \mathrm{Fe}$, and Mn perovskitetype materials has been studied and the ease of forming oxygen vacancies has been found to increase in the following order: $\mathrm{Mn}<\mathrm{Fe}<\mathrm{Co}$ [2]. Such catalysts are also cheaper than the noble metal supported ones.

Perovskites can be prepared by a conventional solidstate reaction, which results in low disparity and worse catalytic behavior of materials. To obtain materials of higher dispersion a number of synthesis methods have been developed such as hydrothermal synthesis [3], sol-gel and combustion routes $[1,4-6]$, microemulsion route [7], etc. On the other hand, mechanochemical synthesis (MCS) is an alternative preparation method, which combines the main concepts of a green chemistry

*corresponding author; e-mail: zzhel@ic.bas.bg approach and a proper inexpensive technology very suitable for industrial application [8-12]. Some of the main properties of mechanochemistry are very suitable for synthesis of new and advanced materials, as well as of highly effective catalyst preparation either as a step or as a main stage of preparation. Mechanical activation changes the overall reactivity of solids.

Previous studies show preparation of Co-, Fe- and MnLa-containing perovskite materials by high-energy grinding of mixture of respective oxide powders [9-12]. In order to improve the synthesis and to increase the materials dispersion there were done different investigations on mechanochemical formation of hydroxide materials and preparation of perovskite after their thermal treatment and washing $[12,13]$. The detail study of $\mathrm{LaMnO}_{3}$ preparation shows the role of water content in starting materials. It influences significantly not only their grinding behavior and mechanochemical reaction rate, but the dispersity of prepared composites, too, i.e. their specific surface area, porosity and particle size [14]. Another approach of preparation of highly dispersed perovskite materials could be a grinding of freshly precipitated initial materials. It is well known that such precursors have a great potential for preparation of good catalysts. This study reports the obtained results on the preparation of $\mathrm{LaMO}_{3}(\mathrm{M}=\mathrm{Co}, \mathrm{Fe}, \mathrm{Mn})$ perovskite catalytic materials by combination of precipitation and mechanochemical method. Characterization of intermediates and synthesized samples was provided by powder X-ray diffraction (XRD), Mössbauer spectroscopy, infrared spectroscopy (IR) and X-ray photoelectron measurements (XPS).

\section{Experimental}

\subsection{Sample preparation}

Studied perovskite materials were prepared by precipitation of respective precursors followed by their mechanochemical activation (MA) with $\mathrm{La}_{2} \mathrm{O}_{3}$. The preparation procedure was as follows: aqueous solutions of $\mathrm{Mn}\left(\mathrm{NO}_{3}\right)_{3} \cdot 4 \mathrm{H}_{2} \mathrm{O}$ (Alfa Aesar, $99.9 \%$ ) or $\mathrm{Co}\left(\mathrm{NO}_{3}\right)_{3}$. 
$6 \mathrm{H}_{2} \mathrm{O}$ (Sigma-Aldrich, 99.99\%) and $\mathrm{Fe}\left(\mathrm{NO}_{3}\right)_{3} \cdot 9 \mathrm{H}_{2} \mathrm{O}$ (Sigma-Aldrich, 99.99\%) were precipitated using solution of $\mathrm{NaOH}$ (Sigma-Aldrich, pellets, $\geq 97 \%$ ) added slowly at continuous stirring. After that the obtained precipitates were washed during filtering while the solution $\mathrm{pH}$ reached neutral value. The samples were dried $12 \mathrm{~h}$ at $60^{\circ} \mathrm{C}$. High energy planetary ball mill PM 100, Retsch, Germany was used for MA. The stoichiometric quantity of $\mathrm{La}_{2} \mathrm{O}_{3}$ (Alfa Aesar, 99.995\%) was added to obtained materials. Then the mixtures were milled for $6 \mathrm{~h}$ at rotation speed of $600 \mathrm{rpm}$. The weight ratio between balls and powder was 12:1.

\subsection{Sample characterization}

Powder X-ray diffraction (XRD) patterns were collected using a TUR-M62 apparatus (Germany) with Co$\mathrm{K}_{\alpha}$ radiation. Data interpretation was carried out using the JCPDS database. Average crystallite sizes and microstrains were determined from the Williamson-Hall diagram [15]. The Mössbauer spectra were obtained at room temperature with a spectrometer Wissenschaftliche Elektronik GMBN, Germany working in a constant acceleration mode using ${ }^{57} \mathrm{Co} / \mathrm{Rh}$ (activity $\approx 50 \mathrm{mCi}$ ) source and $\alpha$-Fe standard. The parameters of hyperfine interaction - isomer shift (IS), quadrupole splitting (QS) and magnetic hyperfine field $\left(H_{\mathrm{hf}}\right)$ as well as the line widths (FWHM) and the relative spectral area $(G)$ of the partial components of the spectra were determined. Values of errors are on the order of $\pm 0.01 \mathrm{~mm} / \mathrm{s}$ for the IS, $\pm 0.02 \mathrm{~mm} / \mathrm{s}$ for the $\mathrm{QS}, \pm 2 \mathrm{~T}$ for $\mathrm{H}_{\mathrm{eff}}, 0.4 \mathrm{~mm} / \mathrm{s}$ for FWHM and $\pm 2 \%$ for $G$, respectively. IR spectra of the samples were recorded by a Nicolet 6700 FTIR spectrometer (Thermo Electron Corporation, USA) in the middle $\left(400-4000 \mathrm{~cm}^{-1}\right)$ and far $\left(250-600 \mathrm{~cm}^{-1}\right)$ regions using $\mathrm{KBr}$ pellets. X-ray photoelectron measurements (XPS) have been carried out on the ESCALAB MkII (VG Scientific) electron spectrometer at a base pressure in the analysis chamber of $5 \times 10^{-10}$ mbar using $\mathrm{Al} \mathrm{K}_{\alpha} \mathrm{X}$-ray source $(200 \mathrm{~W})$ with excitation energies of $1486.6 \mathrm{eV}$. The energy scale has been calibrated by normalizing the $\mathrm{C} 1 \mathrm{~s}$ line of adsorbed adventitious hydrocarbons to $285.0 \mathrm{eV}$. The relative concentrations of the different chemical species are determined based on normalization of the peak areas to their photoionization cross-sections, calculated by Scofield [16].

\section{Results and discussion}

\subsection{XRD analysis}

XRD patterns of precipitated precursors can be seen in Figs. 1a, 2a, and 3a. They are characteristic for the following phases: ferrihydrite and $\alpha-\mathrm{FeOOH}$ (Fig. 1a), $\mathrm{Mn}_{3} \mathrm{O}_{4}$ (Fig. 2a) or $\mathrm{Co}(\mathrm{OH})_{2}$ (Fig. 3a), respectively. The presented diffractograms show halo and broad lines of low intensity in first two cases or well crystallized $\mathrm{Co}(\mathrm{OH})_{2}$ phase in the last case. Mechanochemical milling of obtained precursors with stoichiometric quantity of $\mathrm{La}_{2} \mathrm{O}_{3}$ leads to preparation of respective perovskite materials with cubic crystal structure. Figure $1 \mathrm{~b}$ presents the wellpronounced peaks corresponding to $\mathrm{LaFeO}_{3}$ (PDF-750541). Figure $2 \mathrm{~b}$ shows the powder X-ray diffraction of $\mathrm{LaMnO}_{3}$ (PDF-75-0440). However in the diffraction pattern of Co-containing perovskite it can be seen the registration of hydroxide phase in addition to the perovskite material (Fig. 3b). According to the reference data [8] this can be avoided with treatment of initial material.

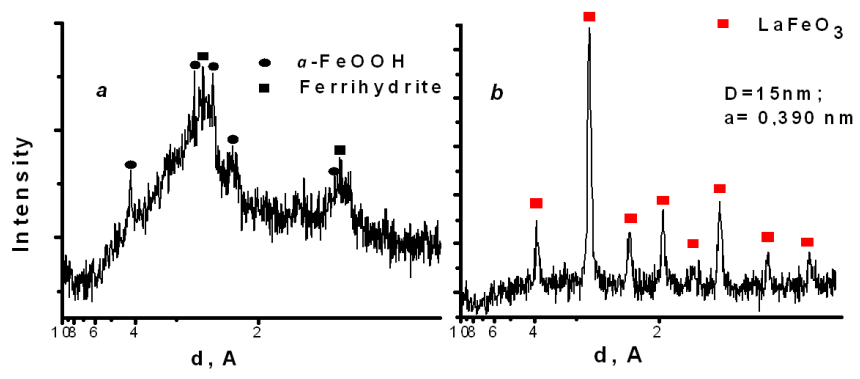

Fig. 1. XRD spectrum of: (a) precipitated iron hydroxide precursor, (b) $\mathrm{LaFeO}_{3}$ obtained by mechanochemical processing.

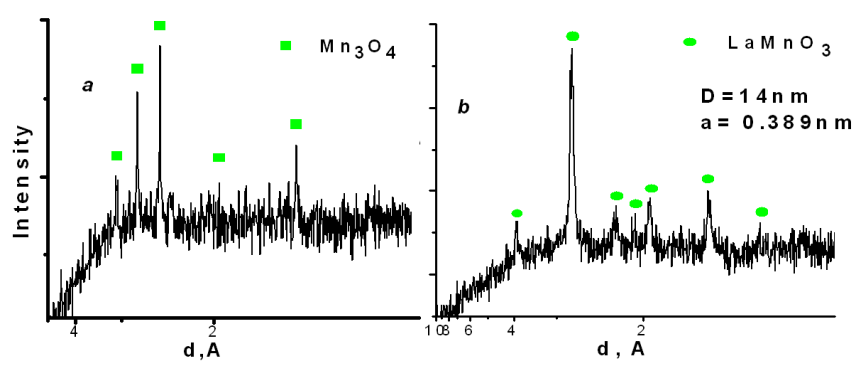

Fig. 2. XRD spectrum of: (a) precipitated $\mathrm{Mn}_{3} \mathrm{O}_{4}$ precursor, (b) $\mathrm{LaMnO}_{3}$ obtained by mechanochemical processing of MA precursor.

Mechanoactivation of cobalt containing precursor for $3 \mathrm{~h}$ (weight ratio balls/powders $=5: 1,600 \mathrm{rpm}$ ) results in decrease of crystallinity degree, as well as in formation of a new phase of $\mathrm{Co}_{3} \mathrm{O}_{4}$ (Fig. 3c). Prolonged mechanical treatment leads to increase of spinel cobalt oxide phase and decrease of hydroxide phase (not shown), but preparation of such initial material did not lead to better results. Therefore, $\mathrm{La}_{2} \mathrm{O}_{3}$ was added to as-prepared after $3 \mathrm{~h}$ milling cobalt precursor and the mixture was milled for $6 \mathrm{~h}$ at $600 \mathrm{rpm}$. This leads to the formation of single phase $\mathrm{LaCoO}_{3}$ (PDF-75-0279) (Fig. 3d). Estimation of unit cell parameters and average crystallite sizes was done by evaluation of recorded spectra of obtained monophase materials (Figs. 1b, 2b, and 3d). Calculated values are presented in the respective figures. The error margins are $\pm 0.005 \mathrm{~nm}$ for unit cell parameters and $\pm 3 \mathrm{~nm}$ for the average crystallite sizes.

\subsection{Mössbauer spectroscopy}

The Mössbauer spectra of iron containing samples were registered (Fig. 4). They include superposition of doublet and sextet part. Spectra evaluation was done as an 


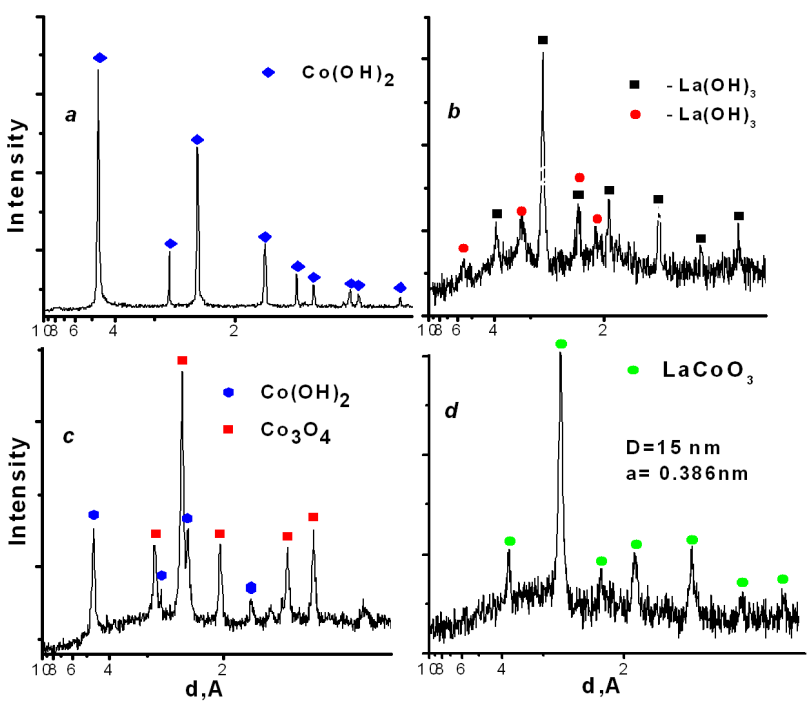

Fig. 3. XRD spectrum of: (a) precipitated cobalt hydroxide precursor, (b) $\mathrm{LaCoO}_{3}$ obtained by its MA, (c) MA cobalt hydroxide precursor, (d) $\mathrm{LaCoO}_{3}$ obtained by MA of milled precursor.

optimal fit of component superposition. It can be seen that the spectrum of prepared iron hydroxide precursor (Fig. 4a) includes a paramagnetic doublet (about 86\%) and lower quantity of sextet component (about 14\%).

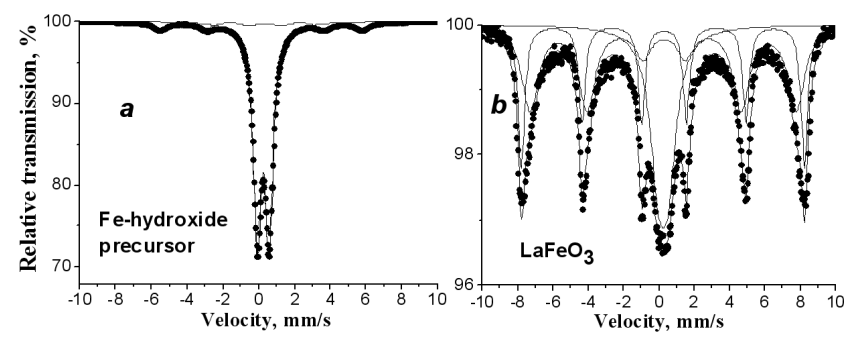

Fig. 4. Mössbauer spectrum of: (a) precipitated iron hydroxide precursor, (b) $\mathrm{LaFeO}_{3}$ obtained by mechanochemical processing.

The calculated parameter values of these components are respectively IS $=0.34 \mathrm{~mm} / \mathrm{s}$ and $\mathrm{QS}=0.66 \mathrm{~mm} / \mathrm{s}$ for the first component; IS $=0.33 \mathrm{~mm} / \mathrm{s}$, QS $=-0.12 \mathrm{~mm} / \mathrm{s}$ and $\mathrm{H}_{\text {eff }}=35.2 \mathrm{~T}$ for the second component. According to the reference data [17] they are characteristic for iron(III) cations in two phases - ferrihydrite and $\alpha$ $\mathrm{FeOOH}$, respectively. Three different components can be resolved in the second spectrum (Fig. 4b). Two of them are sextet components having very close calculated values of IS $=0.36-0.37 \mathrm{~mm} / \mathrm{s}$ and $\mathrm{QS}=0.03 \mathrm{~mm} / \mathrm{s}$, but different $\mathrm{H}_{\mathrm{eff}}=49.8$ and $46.9 \mathrm{~T}$. These hyperfine parameters are typical of $\mathrm{Fe}^{3+}$ ions in octahedral coordination in La-perovskite structure.

However the values of the hyperfine magnetic field are lower in comparison to that for a bulk well crystallized material. The registered $\mathrm{H}_{\text {eff }}$ values are close to previously reported $\mathrm{H}_{\mathrm{eff}}=48.9 \mathrm{~T}$ for mechanically milled
$\mathrm{LaFeO}_{3}$ [18]. The third spectra component is doublet with IS $=0.34 \mathrm{~mm} / \mathrm{s}$ and QS $=0.55 \mathrm{~mm} / \mathrm{s}$, which can be also attributed to iron(III) cations in nanosized $\mathrm{LaFeO}_{3}$ particles with superparamagnetic behavior [18]. Therefore, the obtained spectra components can be regarded as $\mathrm{Fe}^{3+}$-ions in octahedral coordination in $\mathrm{LaFeO}_{3}$ lattice, that belong to particles having different size. The Mössbauer study results are in very good agreement with those obtained with XRD.

\subsection{IR spectroscopy}

IR study in the middle and far regions of prepared materials gives qualitative characterization of the samples (Fig. 5). Bands at wave numbers less than $600 \mathrm{~cm}^{-1}$ are connected with metal-oxygen vibrations. Comparison of the samples' spectra under $600 \mathrm{~cm}^{-1}$ with the spectrum of the $\mathrm{La}_{2} \mathrm{O}_{3}$ pure substance directs to conclusion that almost all amount of $\mathrm{La}_{2} \mathrm{O}_{3}$ has reacted. The shift of the band at $388 \mathrm{~cm}^{-1}$ toward higher wave numbers (for $\mathrm{La}_{2} \mathrm{O}_{3}$ ) and the bands at 355/346, 566/529, and $600 \mathrm{~cm}^{-1}$ are assigned to formation of new phase(s). Bands at $855 \mathrm{~cm}^{-1}$ and the wide band in the region 1250-1750 $\mathrm{cm}^{-1}$ are characteristic of carbonates and hydrocarbonates adsorbed on the sample surface [19]. The complex bands around $1480 \mathrm{~cm}^{-1}$ allow affirming that the ratio between carbonates and hydrocarbonates varies. The carbonates predominate in the case of samples $\mathrm{LaFeO}_{3}$ and $\mathrm{LaCoO}_{3}$. Bands at about 3412 and 1635 and $2900 \mathrm{~cm}^{-1}$ are characteristic for the presence of $\mathrm{H}$-bound $\mathrm{OH}$ groups and physically adsorbed water molecules on the surface and hydrocarbons.

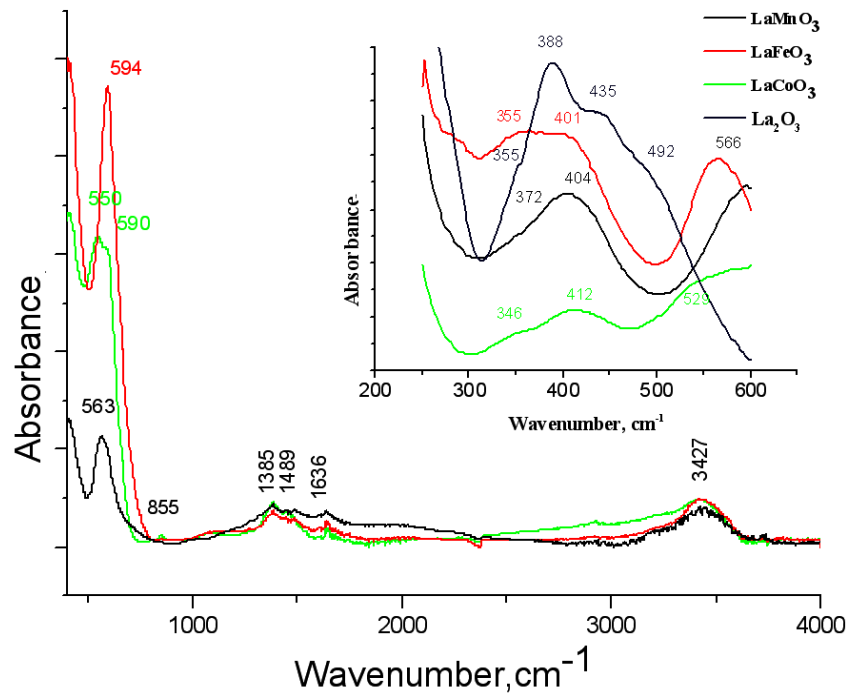

Fig. 5. IR spectra of synthesized perovskites in the middle region and in the far region (inset).

\subsection{X-ray photoelectron spectroscopy}

In order to determine the oxidation states and surface atomic concentration of the elements presented we 
performed XPS study. The XP spectra of $\mathrm{LaMO}_{3}$ $(\mathrm{M}=\mathrm{Fe}, \mathrm{Mn}, \mathrm{Co})$ are presented in Fig. 6. Figure 6a reveals that the spectrum of La consists of different oxidation type lanthanum for all three samples. The line

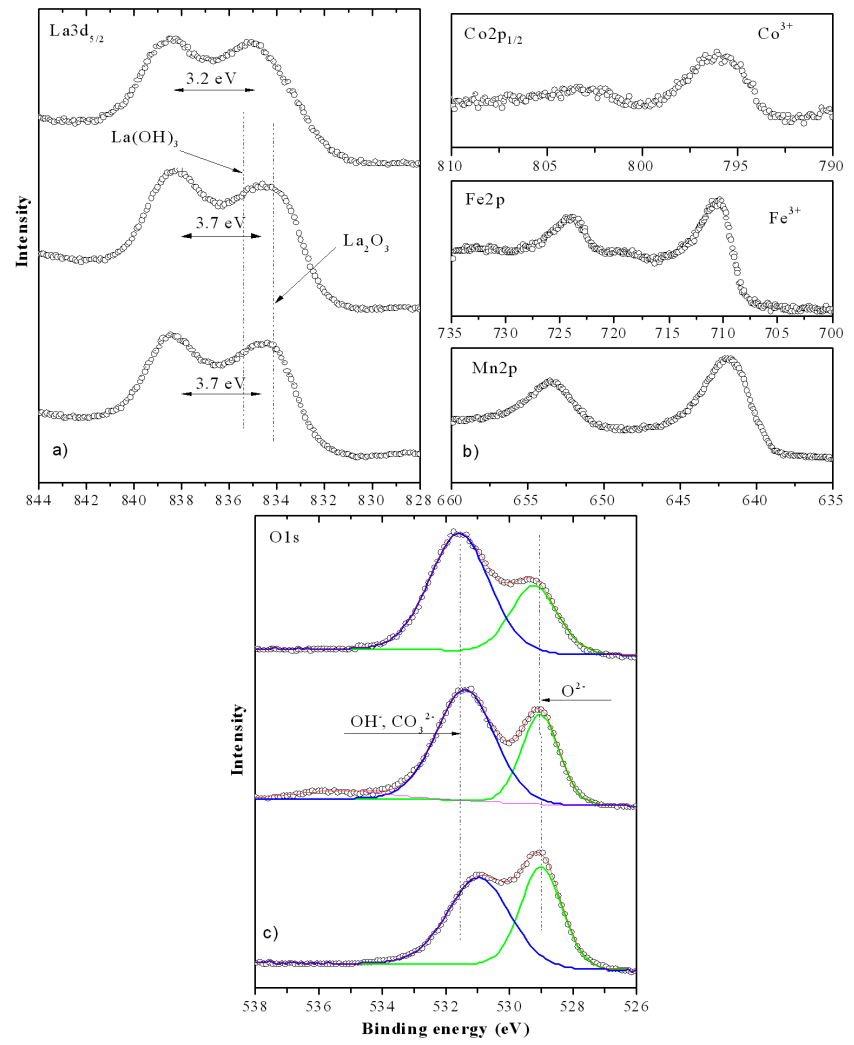

Fig. 6. XPS high-resolution spectra of $\mathrm{LaMO}_{3}$ : (a) La $3 d$, (b) M $2 p$ (M = Fe, Mn, Co) and (c) curve fitted O1s.

shape, binding energy (BE) and FWHM show that the peak can be curve fitted with two subpeaks with different ratio between them depending on sample. Using reference spectra these subpeaks can be ascribed as $\mathrm{La}^{3+}$ in $\mathrm{La}_{2} \mathrm{O}_{3}$ and $\mathrm{La}(\mathrm{OH})_{3}$ and/or $\mathrm{La}_{2}\left(\mathrm{CO}_{3}\right)_{3}$, which is in a very good agreement with IR analysis [20]. Surface atomic concentrations of all three samples $\mathrm{LaMO}_{3}$ (M $=\mathrm{Fe}, \mathrm{Mn}, \mathrm{Co})$ are given in Table. The estimated ratio between the elements differs from the theoretically expected 1:1:3. This discrepancy can be explained with the contamination of lanthanum carbonates and lanthanum hydroxides observed on the surface of the samples. Almost $2 / 3(1 / 2)$ of measured lanthanum is connected with $\mathrm{OH}^{-}$and/or $\mathrm{CO}_{3}^{2-}$ groups for $\mathrm{LaFeO}_{3}$ and $\mathrm{LaCoO}_{3}$ $\left(\mathrm{LaMnO}_{3}\right)$. In this way we can estimate ratio La:M $\approx 1: 1$ $(\mathrm{M}=\mathrm{Fe}, \mathrm{Mn}, \mathrm{Co})$.

Figure $6 \mathrm{~b}$ represents the $\mathrm{Fe} 2 p$ peak. The registered $\mathrm{BE}$ and line shape together with the existence of shakeup satellite at $\approx 719 \mathrm{eV}$ is typical for $\mathrm{Fe}^{3+}$ oxidation state. The measured BE of Mn $2 p$ peak (Fig. 6b) is typical for $\mathrm{Mn}^{3+}$ oxidation state. Figure $6 \mathrm{~b}$ shows Co $2 p_{1 / 2}$ peak, too. The $\mathrm{BE}$ and line shape together with the existence of weak shakeup satellite at $\approx 800-805 \mathrm{eV}$ is typical for
TABLE I

Surface atomic concentrations, at. \%

\begin{tabular}{l|c|c|c}
\hline \hline & La3d & Fe2p/Mn2p/Co2p & O1s \\
\hline $\mathrm{LaFeO}_{3}$ & 24 & 7 & 69 \\
$\mathrm{LaMnO}_{3}$ & 24 & 11 & 65 \\
$\mathrm{LaCoO}_{3}$ & 25 & 9 & 66
\end{tabular}

$\mathrm{Co}^{3+}$ oxidation state.

The all three samples oxygen peak (Fig. 6c) can be fitted with two subpeaks, which are ascribed to $\mathrm{OH}^{-}$ and/or $\mathrm{CO}_{3}^{2-}$ groups with higher $\mathrm{BE}$ and $\mathrm{O}^{2-}$ with lower $\mathrm{BE}$. The ratio between both subpeaks is close to $1: 3$, 1:1 and 1:2 for $\mathrm{LaFeO}_{3}, \mathrm{LaMnO}_{3}$ and $\mathrm{LaCoO}_{3}$, respectively. Therefore, we can recalculate that the oxygen for all three samples is in the range of $25-35$ at.\%. Thus, the ratio La:M:O $\approx 1: 1: 3(\mathrm{M}=\mathrm{Fe}, \mathrm{Mn}, \mathrm{Co})$, as expected for $\mathrm{LaMO}_{3}(\mathrm{M}=\mathrm{Fe}, \mathrm{Mn}, \mathrm{Co})$. As a conclusion we can say that the synthesized compounds are $\mathrm{LaFeO}_{3}, \mathrm{LaMnO}_{3}$, and $\mathrm{LaCoO}_{3}$. Because of the high chemical activity of the lanthanum element we have observed some impurity of La-carbonates and La-hydroxides on the surface of these samples, determined only by the surface sensitive XPS and IR techniques.

Synthesis of freshly synthesized compounds and their mechanoactivation can give rise to completely different results from those of MA of oxides. The phenomena of aggregation and agglomeration responsible for coarsening of size distribution during milling and mechanical activation are affected by the presence of water. Mechanical activation of hydroxides and oxyhydroxides lead to mechanically induced dehydroxylation and to formation of a porous substance with higher surface area and lower crystallite size [8]. Presented investigation shows a possibility to prepare perovskites with comparable characteristics (high dispersion, nanometric crystallite size about 10 $20 \mathrm{~nm}$, presence of oxygen vacancies) with previously reported studies [10-14] but using different synthesis procedure. The milling conditions are also comparable [10-14].

\section{Conclusions}

Perovskite-type $\mathrm{LaMO}_{3}(\mathrm{M}=\mathrm{Co}, \mathrm{Fe}, \mathrm{Mn})$ materials have been successfully prepared by a facile and environmentally friendly method starting from freshly precipitated Fe, Mn and Co oxides/hydroxides and their mechanical milling with lanthanum oxide. Single phase of $\mathrm{LaMO}_{3}$ was obtained at room temperature, without any heating. In the case of $\mathrm{Fe}$ and $\mathrm{Mn}$ compounds the synthesis was done directly by milling of precursor and $\mathrm{La}_{2} \mathrm{O}_{3}$ but for $\mathrm{Co}$-containing sample the single phase perovskite was synthesized after additional mechanoactivation of precipitated material. The spectroscopic data collected by XRD, Mössbauer spectroscopy, IR and XPS techniques reveal the properties of obtained materials. The prepared perovskites have nanometric crystallite size (about $15 \mathrm{~nm}$ ), high dispersion, high degree of microstrains and high level of oxygen vacancies. Such charac- 
teristics will be valuable for catalytic behavior of synthesized materials.

\section{Acknowledgments}

The financial support by the European Social Fund within the framework of Operating Program "Development of Human Resources" (BG051PO001-3.3.060050) for the preparation of this paper is gratefully acknowledged.

\section{References}

[1] R. Köferstein, S. Ebbinghaus, Solid State Ionics 231, 43 (2013).

[2] N. Lakshminarayanan, J. Kuhn, S. Rykov, J.M. Millet, U. Ozkan, Catal. Today 157, 446 (2010).

[3] W. Zheng, R. Liu, D. Peng, G. Meng, Mater. Lett. 43, 19 (2000).

[4] X.P. Dai, Q.Wu, R.J. Li, C.C. Yu, Z.P. Hao, J. Phys. Chem. B 110, 25856 (2006).

[5] Z. Wei, Y. Xua, H. Liu, C. Hu, J. Hazard. Mater. 165, 1056 (2009).

[6] P. Dinka, A.S. Mukasyan, J. Power Source 167, 472 (2007).

[7] A. Giannakas, A. Ladavos, P. Pomonis, Appl. Catal. B Environ. 49, 147 (2004)

[8] P. Baláž, M. Achimovičová, M. Baláž, P. Billik, Z. Cherkezova-Zheleva, J.M. Criado, F. Delogu, E. Dutková, E. Gaffet, F.J. Gotor, R. Kumar, I. Mitov, T. Rojac, M. Senna, A. Streletskii, K. WieczorekCiurowa, Chem. Soc. Rev. 42, 7571 (2013).
[9] K. Wieczorek-Ciurowa, K. Gamrat, Mater. Sci.Poland 25, 219 (2007).

[10] S. Kaliaguine, A. Van Neste, V. Szabo, J.E. Gallot, M. Bassir, R. Muzychuk, Appl. Catal. A Gen. 209 345 (2001).

[11] Q. Zhang, F. Saito, J. Alloys Comp. 297, 99 (2000).

[12] P. Ciambelli, V. Palma, S.F. Tikhov, V.A. Sadykov, L.A. Isupova, L. Lisi, Catal. Today 47, 199 (1999).

[13] T. Ito, Q. Zhang, F. Saito, Powder Technol. 143144, 170 (2004).

[14] S. Ohara, H. Abe, K. Sato, A. Kondo, M. Naito, J. Eur. Ceram. Soc. 28, 1815 (2008).

[15] G.K. Williamson, W.H. Hall, Acta Metall. 1, 22 (1953).

[16] J.H. Scofield, J. Electron Spectrosc. Relat. Phenom. 8, 129 (1976)

[17] R.M. Cornell, U. Schwertmann, The Iron Oxides, Wiley-VCH, Weinheim 2003.

[18] F.J. Berry, X. Ren, J.R. Gancedo, J.F. Marco, Hyperfine Interact. 156-157, 335 (2004).

[19] L.H. Little, Infrared Spectra of Adsorbed Species, Academic Press, London 1966, LCCCN: 65-27318.

[20] G. Tyuliev, D. Panayotov, I. Avramova, D. Stoichev, Ts. Marinova, Mater. Sci. Eng. C 23, 117 (2003). 